\title{
Colletotrichum dematium Produces Phytotoxins in Anthracnose Lesions of Mulberry Leaves
}

\author{
S. Yoshida, S. Hiradate, Y. Fujii, and A. Shirata
}

First and fourth authors: National Institute of Sericultural and Entomological Science, 1-2 Owashi, Tsukuba, Ibaraki 305-8634, Japan; and second and third authors: National Institute of Agro-Environmental Sciences, 3-1-1 Kan-nondai, Tsukuba, Ibaraki 305-8604, Japan. Accepted for publication 30 November 1999.

\begin{abstract}
Yoshida, S., Hiradate, S., Fujii, Y., and Shirata, A. 2000. Colletotrichum dematium produces phytotoxins in anthracnose lesions of mulberry leaves. Phytopathology 90:285-291.

Colletotrichum dematium, the causal agent of mulberry anthracnose, was examined to produce phytotoxins in vitro and in planta. Raw and autoclaved mulberry leaves infected with the fungus, as well as the fungus incubated with several solid or liquid media, were extracted with acetone. Extracts obtained from the fungus grown on raw and autoclaved mulberry leaves caused brown necrotic lesions on susceptible mulberry leaves when they were placed $(10 \mu \mathrm{l})$ on the wounded adaxial surface. Whereas, no extracts obtained from media, except inoculated medium containing

homogenized mulberry leaves, induced the necrosis, suggesting that the fungus produced phytotoxins in planta and that some components in mulberry leaves may be indispensable substrates for producing the toxins. The phytotoxins obtained from the diseased leaves induced necrosis on nonhost plants leaves as well as on mulberry leaves. The toxins were present in the border of anthracnose lesions on the leaves, and the sensitivity to the toxin correlated with that to the fungus infection in each susceptible or resistant mulberry cultivar. These results suggest that the phytotoxins are host nonspecific and play a role in fungal pathogenesis in the development of the lesions. Four toxic compounds were isolated and purified from anthracnose lesions. However, due to the low yield, the chemical structure of the compounds could not be identified.
\end{abstract}

Mulberry anthracnose caused by Colletotrichum dematium is a common leaf disease of mulberry in Japan $(9,26)$. The incidence of the fungal disease has tended to increase due to dense planting of the trees and the mechanical harvesting of the shoots that results in significant damage to tree vigor. The severe occurrence of the disease leads to a loss of yield of leaves for silkworm feeding. The leaves infected with the fungus display brown necrotic spots or streaks and, particularly in summer, halos are formed around the lesions $(9,26)$. Several bacterial diseases, such as tobacco wildfire caused by Pseudomonas tabaci, produce similar lesions accompanied with halos (19). The formation of halos in bacterial diseases is usually due to the inhibition of amino acid synthesis by phytotoxins of the bacteria (10). We, therefore, hypothesized that the anthracnose fungus also produced phytotoxins in mulberry lesions that were involved in the pathogenic process. However, the production of phytotoxins in the lesions of mulberry leaves by $C$. dematium had not been hitherto reported.

It is generally recognized that toxins produced by phytopathogenic fungi consist of host-specific and host-nonspecific toxins (23). The former toxins are produced by several fungi, such as Alternaria spp. and Helminthosporium spp. $(12,13)$, and are major agents of virulence or pathogenicity (21). The latter toxins affect plants in general as well as animals (23). Ouchi (15) reported that some of the toxins were involved in the appearance of lesions in plant diseases and are considered to be virulence factors (10). Both toxins can be distinguished based on their physiological properties such as host specificity and biological role $(10,16,23)$.

Phytotoxin production has been reported for several Colletotrichum species (1). The toxins of which the chemical structure was identified include colletotrichins produced by $C$. nicotianae (6) and $C$. capsici (8), colletopyrone produced by $C$. nicotianae

Corresponding author: S. Yoshida; E-mail address: yoshige@ nises.affrc.go.jp

Publication no. P-2000-0126-02R

(c) 2000 The American Phytopathological Society
(5), aspergillomarasmins produced by C. gloeosporioides (2) and ferricrocin produced by $C$. gloeosporioides (14). These toxins are regarded as host-nonspecific toxins. In addition, $C$. fuscum (7), $C$. camelliae (22), C. capsici $(3,11)$, and C. gloeosporioides (20) have been reported to produce toxins of which the structure was not identified. The above toxins produced by Colletotrichum species were recovered only from the culture media (culture filtrates), while no reports of toxins occurring in infected tissues (1) such as vivotoxin (4) are available.

The first objective of this study was to determine whether $C$. dematium produced phytotoxins in anthracnose lesions on mulberry leaves and in several culture media. Once it was revealed that the fungus produced phytotoxins in leaf lesions, the second objective was to define the role of the phytotoxins in the pathogenesis of the fungus to mulberry leaves and to isolate and purify the toxins in order to determine their chemical structure.

\section{MATERIALS AND METHODS}

Strains and media. The mulberry anthracnose fungus used in the study was $C$. dematium (culture S8901) preserved in our laboratory. Media used for incubation of the fungus were potato sucrose agar (PSA), potato dextrose agar (PDA), mulberry leaf decoction sucrose agar (MSA: dried mulberry leaf, $50 \mathrm{~g}$; sucrose, $30 \mathrm{~g}$; agar, $27 \mathrm{~g}$; and distilled water, 1.5 liter), King's B (KB: proteose peptone No. 3 [Difco Laboratories, Detroit], $20 \mathrm{~g} ; \mathrm{K}_{2} \mathrm{HPO}_{4}, 1.5 \mathrm{~g}$; $\mathrm{MgSO}_{4}, 1.5 \mathrm{~g}$; glycerin, $10 \mathrm{ml}$; agar, $15 \mathrm{~g}$; and distilled water, 1 liter), Richards $\left(\mathrm{KNO}_{3}, 10 \mathrm{~g} ; \mathrm{KH}_{2} \mathrm{PO}_{4}, 5 \mathrm{~g} ; \mathrm{MgSO}_{4} \cdot 7 \mathrm{H}_{2} \mathrm{O}, 2.5 \mathrm{~g} ; \mathrm{FeCl}_{3}\right.$, $5 \mathrm{mg}$; sucrose, $50 \mathrm{~g}$; agar, $18 \mathrm{~g}$; and distilled water, 1 liter), and Czapek $\left(\mathrm{NaNO}_{3}, 2 \mathrm{~g} ; \mathrm{K}_{2} \mathrm{HPO}_{4}, 1 \mathrm{~g} ; \mathrm{MgSO}_{4} \cdot 7 \mathrm{H}_{2} \mathrm{O}, 0.5 \mathrm{~g} ; \mathrm{KCl}\right.$, $0.5 \mathrm{~g} ; \mathrm{FeSO}_{4}, 10 \mathrm{mg}$; sucrose, $30 \mathrm{~g}$; agar, $18 \mathrm{~g}$; and distilled water, 1 liter), and their liquid media lacking agar. In addition, homogenized mulberry leaf agar (HMA: raw mulberry leaf homogenized for $3 \mathrm{~min}, 145 \mathrm{~g}$; agar, $18 \mathrm{~g}$; and distilled water, 1 liter) and the liquid lacking agar were used as media for $C$. dematium. The quantity of mulberry leaf used for preparing HMA was approximately equal to that used for MSA on a dry weight basis. 
Toxin extraction from culture media. A small mycelial block (20 to $30 \mathrm{~mm}^{3}$ ) of $C$. dematium harvested from a 7-day-old PSA plate was transferred to $20 \mathrm{ml}$ of each above solid medium in a petri dish $(9 \mathrm{~cm}$ in diameter) or to $50 \mathrm{ml}$ of each above liquid medium in a $300-\mathrm{ml}$ Erlenmeyer flask. Inoculated media were subsequently incubated at $25^{\circ} \mathrm{C}$ in the dark for 7 days. After incubation, the mycelial colony grown on each medium was extracted with $20 \mathrm{ml}$ of acetone for $30 \mathrm{~min}$, and the extract was then air-dried and concentrated to $0.5 \mathrm{ml}$ by the addition of sterilized distilled water. In the case of liquid media, culture filtrate was obtained from each culture mixture by centrifugation at $5,000 \times g$ for $10 \mathrm{~min}$. The filtrate was concentrated 10 -fold by evaporation or lyophilization and was filter $(0.45 \mu \mathrm{m})$ sterilized. Extract from nontransferred solid or liquid medium was used as a control.

Toxin extraction from infected mulberry leaves. To obtain extract from anthracnose lesions on mulberry leaves, healthy mulberry leaves (cv. Shin-ichinose; Morus alba L.) that were cultivated in the field at the National Institute of Sericultural and Entomological Science, Tsukuba, were sampled, and mycelial blocks of C. dematium harvested from a 10-day-old MSA plate were placed at several puncture sites on the sampled leaves. After incubation in a moist chamber at room temperature for 7 to 10 days, brown anthracnose lesions appearing on the leaves were excised with scissors and soaked in acetone $(10 \mathrm{ml} / \mathrm{g}$ of lesion) for $30 \mathrm{~min}$. The extract was air-dried and concentrated to $200 \mu \mathrm{l} / \mathrm{g}$ of raw lesion with sterilized distilled water. After filter $(0.45 \mu \mathrm{m})$ sterilization, the obtained extract was referred to as "lesion extract." Extract from healthy mulberry leaves was prepared by the same method as described above for the control. Lesions were also extracted with other solvents; anthracnose lesions excised were air-dried and then extracted with ether, ethyl acetate, $n$-butanol, 10 to $100 \%$ acetone, methanol solvents, or distilled water ( $25 \mathrm{ml} / \mathrm{g}$ of dried lesion). Each extract was subsequently concentrated to $1 \mathrm{ml} / \mathrm{g}$ of dried lesion with distilled water.

In addition to the raw leaves, mulberry leaves (cv. Shin-ichinose) autoclaved at $121^{\circ} \mathrm{C}$ for $15 \mathrm{~min}$ were also used for the incubation of $C$. dematium. Five milliliters of a conidial suspension $\left(8 \times 10^{6}\right.$ conidia per $\mathrm{ml}$ ) of the fungus aseptically prepared from the above MSA plates was poured into a 300-ml sterilized Erlenmeyer flask containing $5 \mathrm{~g}$ of autoclaved mulberry leaves, and the inoculated leaves were incubated at $25^{\circ} \mathrm{C}$ for 7 days. Extract was obtained by the same procedure as that used for the lesion extract.

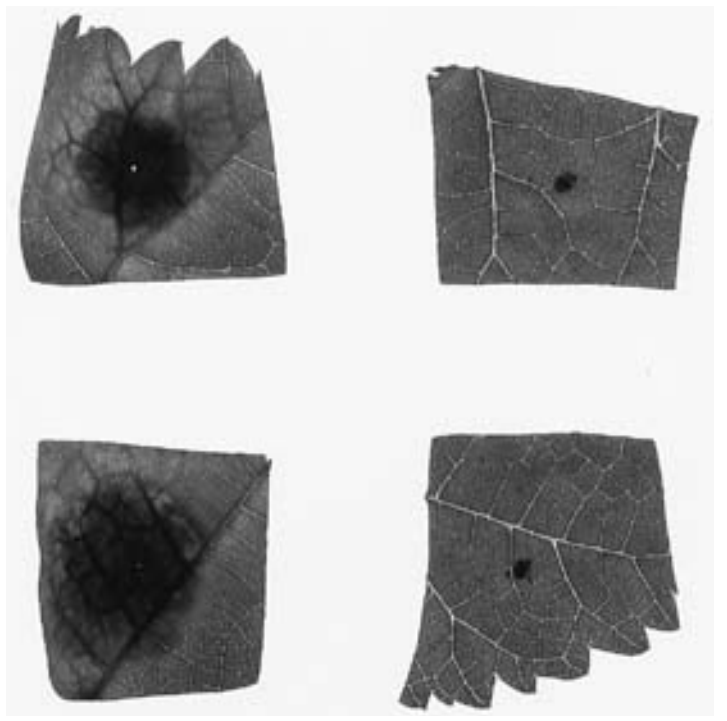

Fig. 1. Necrotic lesions on mulberry leaves (cv. Ochii) appeared 3 days after placing a drop of lesion extract at the puncture site (left). Acetone extract from healthy mulberry leaves was placed on each leaf at the puncture site as a control (right). Black points in the center of the right leaves correspond to the sites that had been punctured and onto which extract had been placed.
Plant toxicity assay. Healthy mulberry leaves of susceptible cv. Ochii (M. multicaulis Perr.) cultivated in the field or in a greenhouse were sampled and cut into 6- to $9-\mathrm{cm}^{2}$ fragments with scissors. Extract obtained from each above culture media and infected leaves $(10 \mu \mathrm{l})$ was then placed on the adaxial surface of the leaves punctured with needles. After incubation for 2 to 3 days in a moist chamber at room temperature, toxicity of the extract was determined by the appearance of necrotic lesions on the leaves (Fig. 1) and degree of toxicity was evaluated based on the diameter of the lesions.

Toxicity of the lesion extract was also evaluated on 17 species of randomly selected plants. The plant leaves grown in the field or a greenhouse were sampled or cut, and $10 \mu \mathrm{l}$ of lesion extract was placed as described above. Likewise, $10 \mu$ of a conidial suspension $\left(5 \times 10^{6}\right.$ conidia per $\left.\mathrm{ml}\right)$ of $C$. dematium prepared as described above was inoculated onto another punctured leaf of each species. After incubation for 6 days in a moist chamber, leaf toxicity was evaluated as described above, and fungal pathogenicity was evaluated by the appearance of necrotic anthracnose lesions.

Toxicity of lesion extract toward cultivars of mulberry leaves. Eight mulberry cultivars grown in the field (approximately 10 to 15 years old) were selected. Each cultivar selected was either susceptible or resistant to $C$. dematium, based on previous studies (27); Ochii, Chyousa, Hikojirou, and Ryuusenshuu were susceptible cultivars, and Kaneko, Gunmaakagi, Yanagida, and Yamatowase were resistant cultivars. A healthy young leaf of each cultivar was sampled in June and cut into fragments as described above. Ten microliters of lesion extract was then placed on the punctured adaxial surface of leaves and toxicity was evaluated after 3 days of incubation as described previously. For ascertaining the susceptibility to $C$. dematium, $10 \mu \mathrm{l}$ of a conidial suspension $\left(2 \times 10^{6}\right.$ conidia per $\left.\mathrm{ml}\right)$ prepared as described above was inoculated onto the adaxial surface of another punctured leaf piece prepared from the same leaf in each cultivar. Susceptibility of each cultivar was evaluated based on the diameter of the round and brown anthracnose lesions after 7 days of incubation in a moist chamber. Results were subjected to Tukey's test.

Toxicity of extract obtained from various parts of anthracnose lesions. Anthracnose lesions on mulberry leaves (cv. Shinichinose) were formed by the inoculation of mycelial blocks of $C$. dematium as described above. Subsequently, lesions that were round and brown were separated using scissors into (i) brown parts; (ii) border parts (approximately $5 \mathrm{~mm}$ wide, including the halo area) between brown parts and healthy parts, surrounding the brown parts; and (iii) healthy parts around the border parts. After being airdried, each part (dry weight, $0.2 \mathrm{~g}$ ) was extracted with $70 \%$ acetone $(10 \mathrm{ml})$ for $60 \mathrm{~min}$ at room temperature, and the extract was air-dried and concentrated to $100 \mu \mathrm{l}$ with $50 \%$ methanol. Toxicity of the concentrated extracts was assayed and assessed as described above. Placing a drop of $50 \%$ methanol solution (only a solvent) does not affect the punctured mulberry leaves. Results were subjected to Tukey's test.

Chemical analysis. To isolate the phytotoxins produced in anthracnose lesions, a large amount of diseased mulberry leaves was prepared as follows: detached mulberry leaves (cv. Shin-ichinose) were cut into 8 - to $12-\mathrm{cm}^{2}$ fragments that were then soaked in a conidial suspension $\left(10^{6}\right.$ conidia per $\left.\mathrm{ml}\right)$ of $C$. dematium prepared as described above. After absorption of excess suspension with paper towels, the inoculated leaves were incubated in moist chambers at room temperature. After 3 to 6 days, diseased cut leaves exhibiting brown anthracnose lesions all over the surface were collected and preserved in a freezer at $-30^{\circ} \mathrm{C}$ until extraction. Three kilograms of the frozen sample (dry weight basis; approximately $650 \mathrm{~g}$ ) was subsequently extracted with 21 liters of acetone for $1 \mathrm{~h}$ at room temperature. The extract was air-dried and dissolved in $500 \mathrm{ml}$ of distilled water for use as crude extract to isolate and identify the toxic compounds. For activity-directed purification, specific toxic activity was determined by placing an appropriate concentration 
of each fractionated sample diluted with $50 \%$ methanol on detached cv. Ochii leaves as described above.

The toxic compounds were finally fractionated by high-pressure liquid chromatography (HPLC) (626 pump and 996 photodiode array detector; Waters, Milford, MA). The separation was achieved using a Shodex C18-5B column $(250 \times 4.6-\mathrm{mm}$ internal diameter; Showadenko, Tokyo) or Shodex PH-5B column $(250 \times 4.6-\mathrm{mm}$ internal diameter; Showadenko) at a flow rate of $1 \mathrm{ml} / \mathrm{min}$ at $40{ }^{\circ} \mathrm{C}$. ${ }^{1} \mathrm{H}-\mathrm{NMR}$ and ${ }^{13} \mathrm{C}-\mathrm{NMR}$ spectra of each isolated compound dissolved in methanol- $d_{4}$ were analyzed with a JNM A600 FTNMR System (JEOL, Tokyo).

\section{RESULTS}

Toxicity of lesion extract. Extract obtained from anthracnose lesions on mulberry leaves induced necrotic lesions on wounded leaves of cv. Ochii, while no lesions were observed when control extracts were used (Fig. 1). The necrosis that was first observed as a darkening of the vein within 1 day after placing the extract then extended to neighboring tissues, resulting in brown necrotic lesions. When dried anthracnose lesions were extracted with other solvents, the extract obtained using 10 to $80 \%$ acetone, methanol, and distilled water caused necrosis on mulberry leaves. Extract

TABLE 1. Formation of necrotic lesions by lesion extract and conidial suspension of Colletotrichum dematium S8901 on leaves of various plants

\begin{tabular}{|c|c|c|c|c|c|c|}
\hline \multirow[b]{2}{*}{ Plant $^{\mathrm{a}}$} & \multicolumn{2}{|c|}{ Lesion extract ${ }^{b}$} & \multicolumn{2}{|c|}{ Control $^{\mathrm{c}}$} & \multicolumn{2}{|c|}{ Conidial suspension ${ }^{\mathrm{d}}$} \\
\hline & Leaf 1 & Leaf 2 & Leaf 1 & Leaf 2 & Leaf 1 & Leaf 2 \\
\hline Soybean (Glycine max) & $+^{e}$ & + & - & - & - & - \\
\hline Japanese pear (Pyrus serotina) & + & + & - & - & - & - \\
\hline Green pepper (Capsicum anпиит var. angulosum) & - & + & - & - & - & - \\
\hline Maple tree (Acer buergerianum) & + & - & - & - & - & - \\
\hline Cucumber (Cucumis sativus) & - & - & - & - & - & - \\
\hline Eggplant (Solanum esculentum) & + & - & - & - & - & - \\
\hline Tulip tree (Liriodendron tulipifera) & ++ & ++ & - & - & + & - \\
\hline Peach (Prunus persica) & +++ & +++ & $(+)$ & - & - & - \\
\hline Yulan (Magnolia denudata) & + & + & - & - & - & - \\
\hline Kudzu-vein (Pueraria thunbergiana) & +++ & +++ & $(+)$ & $(+)$ & - & - \\
\hline Mulberry (cv. Ochii, Morus multicaulis) & +++ & +++ & - & - & +++ & +++ \\
\hline Mulberry (cv. Shimaguwa, Morus acidosa) & + & ++ & - & - & +++ & +++ \\
\hline Paper-mulberry (Broussonetia kazinoki) & - & - & - & - & - & - \\
\hline Silkworm-thorn (Cudrania tricuspidata) & - & - & - & - & - & - \\
\hline Fig (Ficus erecta) & - & - & - & - & - & - \\
\hline Chinese cabbage (Brassica campestris var. pekinensis) & + & + & - & - & - & - \\
\hline Japanese radish (Raphanus sativus var. acanthiformis) & +++ & +++ & - & - & - & - \\
\hline
\end{tabular}

a Each plant was cultivated in the field or a greenhouse, and the detached or cut leaves were used in the experiment.

b Ten microliters of acetone extract from anthracnose lesions was placed on each of two leaves at the puncture site.

c Ten microliters of acetone extract from healthy mulberry leaves was placed on each of two leaves at the puncture site.

d Ten microliters of conidial suspension was drop-inoculated on each of two leaves at the puncture site.

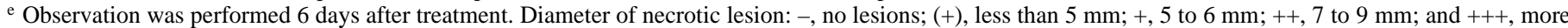
than $10 \mathrm{~mm}$.
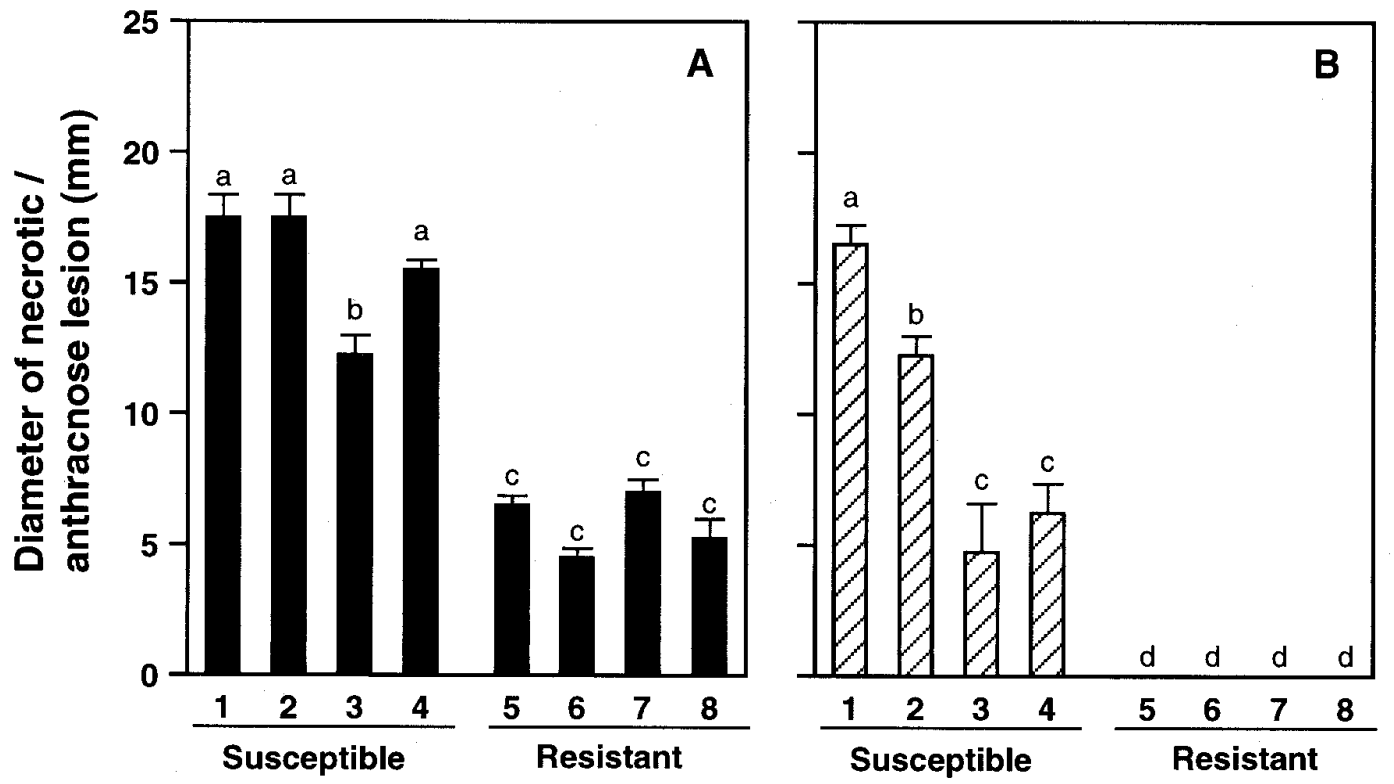

Cultivar

Fig. 2. Toxicity of lesion extract and lesion formation by the inoculation of a conidial suspension of Colletotrichum dematium on leaves of mulberry for each cultivar. A, Necrotic lesion formed by placing a drop of the lesion extract. B, Anthracnose lesion formed by the inoculation of a conidial suspension. Ten microliters of extract or conidial suspension was placed on each leaf at the puncture site, and observations were performed after 3 or 7 days of placing, respectively. Mulberry cultivar: 1, Ochii; 2, Chyousa; 3, Hikojirou; 4, Ryuusenshuu; 5, Kaneko; 6, Gunmaakagi; 7, Yanagida; and 8, Yamatowase. Each value represents the average of four determinations. Bars represent the standard error of the mean. The same letters in each column in $\mathbf{A}$ or $\mathbf{B}$ are not significantly different $(P=$ 0.05 ) according to Tukey's test. Similar results were obtained when the experiment was repeated. 
obtained from the fungus inoculated to autoclaved mulberry leaves also induced necrosis similar to that caused by the lesion extract. When extracts obtained from lesions on raw and autoclaved mulberry leaves were fractionated by two types of prepack cartridge columns, silica (Sep-pak, $690 \mathrm{mg}$ [Waters]; solvents, chloroform and methanol mixtures with stepwise increase of the content of methanol) and C18 (Bond elute, $500 \mathrm{mg}$ [Varian, Harbor City, CA]; solvents, $\mathrm{H}_{2} \mathrm{O}$ and methanol mixtures with stepwise increase of the content of methanol), toxicity was observed in the same fractions of both extracts ( 9.5:0.5 and 9:1; $\mathrm{C} 18$ column, $\mathrm{H}_{2} \mathrm{O} /$ methanol $=4: 6$ and $3: 7$ ).

Toxicity of extract from media incubated with $C$. dematium. No extract obtained from any solid or liquid culture media, except HMA and its liquid, caused necrosis similar to that caused by the lesion extract. Modification of media incubation conditions such as incubation period, light conditions, incubation temperature, and degree of shaking failed to reveal the activity. Although extracts obtained from $\mathrm{KB}$ plate or liquid occasionally induced necrotic lesions, the type differed from that caused by the lesion extract, and the control extract often induced small necrotic lesions. However, culture extracts obtained from HMA and its liquid medium containing only homogenized mulberry leaves produced the necrosis similar to that caused by the lesion extract.

Toxicity of lesion extract toward leaves of various plants. As in the case of mulberry leaves, the lesion extract caused necrosis on the leaves of several plant species (Table 1). Peach, kudzuvine, and Japanese radish leaves were particularly sensitive to the lesion extract, although the control extract also caused minimal necrosis on peach and kudzu-vine leaves. Whereas, a conidial suspension of $C$. dematium induced anthracnose lesions only on a few leaves; the symptoms were observed only on mulberry (cvs. Ochii and Shimaguwa [M. acidosa G.]) and tulip tree leaves.

Toxicity of lesion extract toward cultivars of mulberry leaves. Necrotic lesions induced by the lesion extract were significantly $(P=0.05)$ larger on four susceptible cultivars than on four resis-

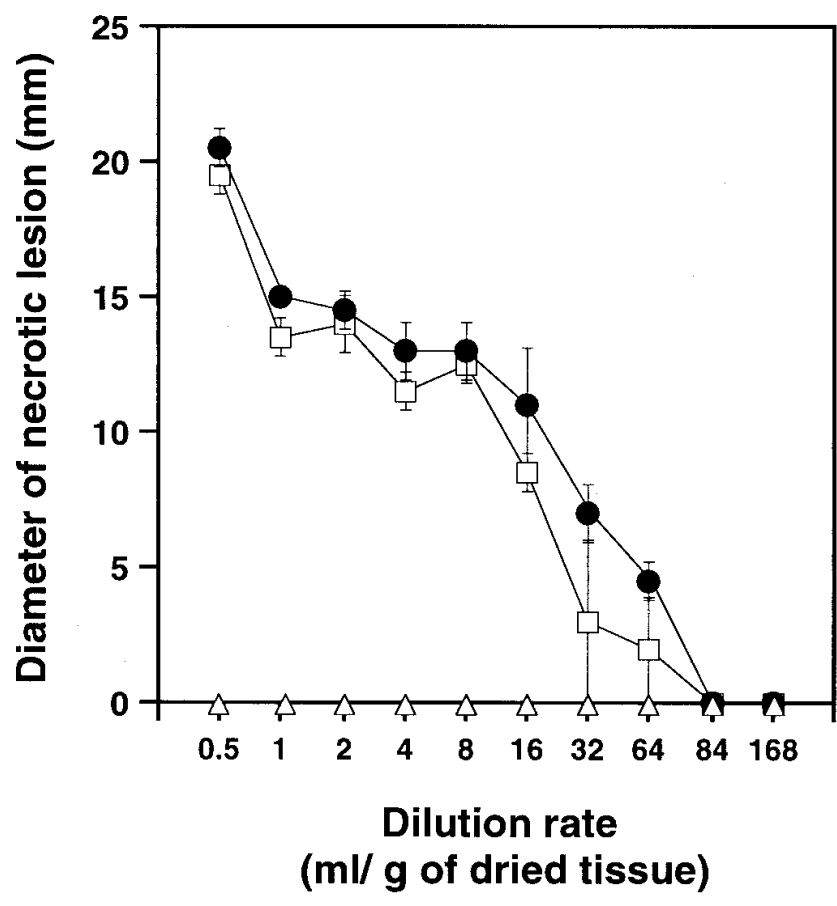

Fig. 3. Toxicity of diluted extract obtained from each part of the lesion on mulberry leaves. Each value represents the average of two determinations. Bars represent the standard error of the mean. Each extract was diluted with $50 \%$ methanol. Symbols: $\square$, extract from brown parts of lesions; $\bullet$, extract from border parts between brown parts and healthy parts; $\Delta$, extract from healthy parts around lesions. Similar results were obtained when the experiment was repeated. tant cultivars (Fig. 2). Similar results were obtained by the inoculation of a conidial suspension of $C$. dematium; anthracnose lesions appeared only on the leaves of susceptible cultivars. Although no lesions appeared on the leaves of resistant cultivars, lesions with a small size (3 to $6 \mathrm{~mm}$ in diameter) were induced when UV rays were irradiated on the abaxial surface of the leaves according to Shirata's method (17), indicating that the fungus caused a latent infection. The average size of necrotic lesions induced by the extract and the average size of anthracnose lesions induced by the conidial suspension in each cultivar were highly correlated with a correlation coefficient $(r)$ of $0.925(P=0.01)$.

Toxicity of extract obtained from various parts of anthracnose lesions. Figure 3 shows the toxicity of the concentrated extract from each part of the lesions. Each concentrated $(0.5$ to $64 \mathrm{ml} / \mathrm{g}$ of dried tissue) extract of the border parts induced the necrotic lesion, and the size was not significantly $(P=0.05)$ different from that elicited by each concentrated extract from brown parts. Toxicity of both extracts to the leaves disappeared at the same concentration ( $128 \mathrm{ml} / \mathrm{g}$ of dried tissue).

Isolation of toxic compounds from anthracnose lesions. Figure 4 shows the isolation procedures of the toxic compounds. Five hundred milliliters of crude extract was fractionated with an equivalent volume of $n$-hexane and ethyl acetate to obtain acidic and neutral fractions. Each fraction was applied to a silica gel column $(400 \times 27-\mathrm{mm}$ internal diameter; Wakogel C-200 [Wako, Tokyo]) and eluted with chloroform, chloroform/methanol mixtures, and methanol. Each active fraction eluted was subsequently applied to a C18 cartridge column $(140 \times 8.5$-mm internal diameter; Analytichem Bondesil C18 PART 1221-3012 [Varian]) and eluted with $\mathrm{H}_{2} \mathrm{O}$, $\mathrm{H}_{2} \mathrm{O}$ /methanol mixtures, and methanol. Active fractions were applied on the HPLC system, yielding four separate compounds (compounds $\mathrm{A}$ to $\mathrm{D}$ ). Yield of each isolated compound was less than the detection limit $(0.1 \mathrm{mg})$. Compound A was most toxic, and almost all toxicity of the crude acetone extract was explained by that of compound A. Compounds B, C, and D were 28, 28, and 43 times less toxic than was compound $\mathrm{A}$, respectively.

Chemical properties of isolated compounds. Due to the very small quantity of isolated compounds, ${ }^{13} \mathrm{C}-\mathrm{NMR}$ and FAB-MS spectra of the compounds (A to D) did not give useful information. Only the ${ }^{1} \mathrm{H}-\mathrm{NMR}$ spectrum of each compound showed very weak signals. In compound A, a signal due to methyl proton at $1.0 \mathrm{ppm}$, methylene proton at $1.3 \mathrm{ppm}$, and protons deriving from aromatic ring were observed. The spectra of compounds B and C were very similar; proton signals at 1.1, 1.3, 1.7, 1.8, 2.3, and $7.2 \mathrm{ppm}$ were observed in both compounds. In compound $\mathrm{D}$, weak signals due to methyl proton at 0.85 to $0.98 \mathrm{ppm}$ and methylene proton at 1.3 , 1.7, and $2.1 \mathrm{ppm}$ were also observed. These spectra suggest that compounds $\mathrm{A}$ to $\mathrm{C}$ have an aromatic ring(s), unlike compound $\mathrm{D}$. Based on the behavior of these compounds during the separation procedures, all would have carboxylic group(s). UV absorption spectra of compounds A to D detected with the photodiode array detector on HPLC separation revealed that each compound showed three similar peaks (approximately 271, 323, and $369 \mathrm{~nm}$ ) of absorption (Fig. 5), suggesting that the chemical structure of the compounds is similar. In addition, when these compounds were dissolved in methanol, they were fluorescent under UV rays at $366 \mathrm{~nm}$.

\section{DISCUSSION}

In this study, we observed that $C$. dematium produced phytotoxins in anthracnose lesions on mulberry leaves. The toxins were also produced when the fungus was incubated in autoclaved mulberry leaves, suggesting that toxicity of those extracts is not originated from the plant response metabolites, such as phytoalexins, but from fungal secondary metabolites. Results of semipurification of the toxins using two kinds of prepack cartridge columns from anthracnose lesions on raw and autoclaved leaves suggest that both (raw and autoclaved) diseased leaves may contain the same or very 
similar active compounds. On the other hand, phytotoxin production was not observed in several solid or liquid media used in this study, even in MSA medium, which contains mulberry leaf decoction. To ascertain whether sugars in MSA medium inhibited toxin production, as reported for bacterial toxins produced by Pseudomonas tolaasii in culture (18), solid or liquid medium containing only the decoction of mulberry leaves prepared without sucrose was used for incubation of the fungus. Consequently, obtained culture extracts did not cause necrosis on the leaves (data not shown), im- plying that the lack of production of toxins in MSA solid or liquid medium may not be due to the presence of sugars. Although necrosis occasionally appeared after the application of $\mathrm{KB}$ culture medium extracts, toxicity may be due to different factors such as concentrated nutrients of the media, because the type of necrosis differed from that caused by the lesion extract and because the control extracts occasionally induced similar necrosis. Thus, the phytotoxins may be specifically produced only in mulberry leaves; certain leaf components (not or less extracted in the decoction)

\section{Acetone extract from diseased leaves (dried wt.650 g) $770 *$}

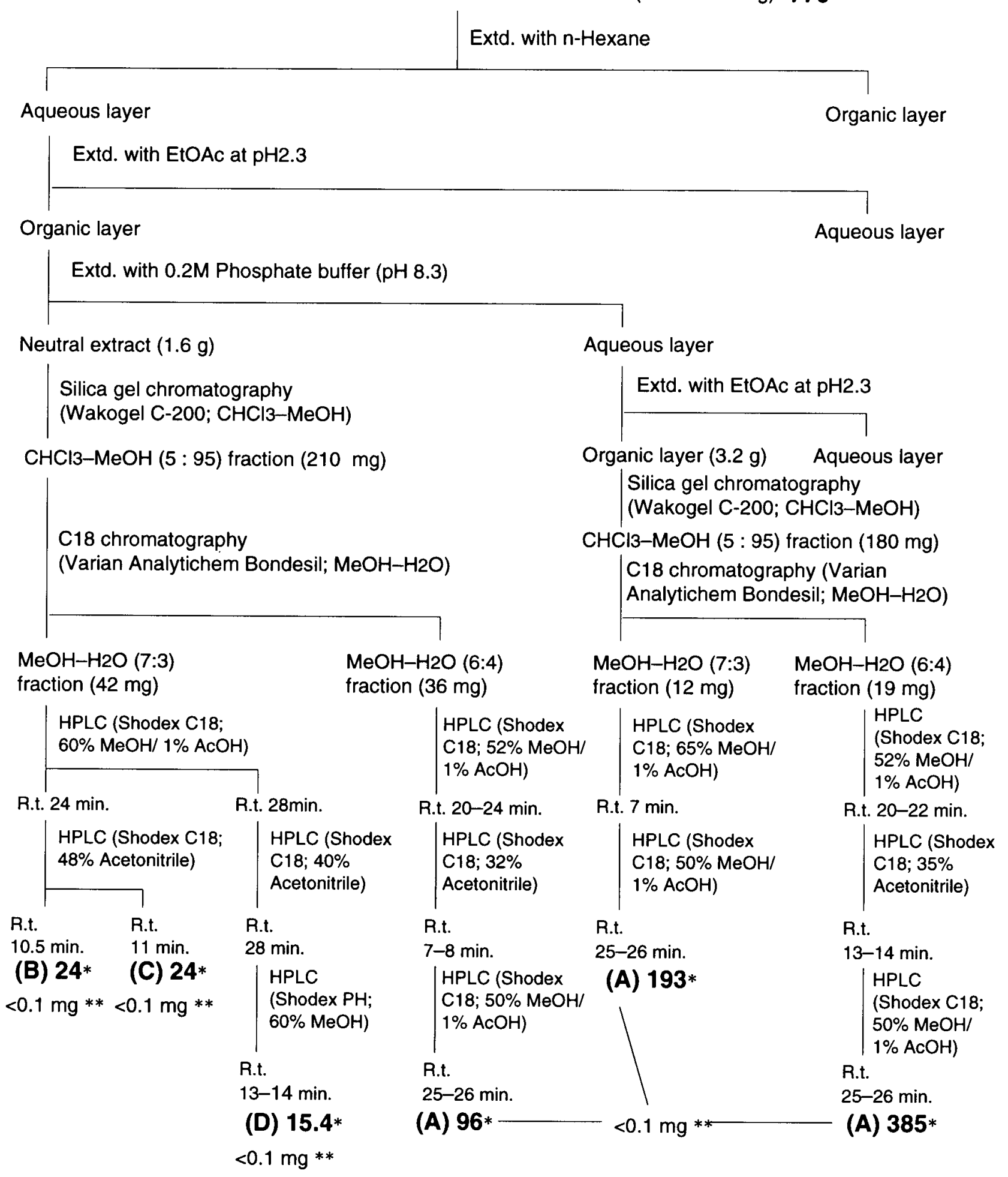

Fig. 4. Isolation procedures of toxic compounds (A to D) from anthracnose lesions on mulberry leaves produced by Colletotrichum dematium. *Concentration $(\mu \mathrm{l} / \mathrm{g}$ of dried lesion) required for producing necrotic lesions of $20 \mathrm{~mm}$ in diameter. **Less than detection limit $(0.1 \mathrm{mg})$. 
might be necessary as the substrates or precursors of the toxins. Indeed, the fungus produced the toxins in HMA and its liquid medium containing only homogenized mulberry leaves.

The phytotoxins affected the leaves of several plants besides mulberry. Pathogenicity of the mulberry pathogen, however, was observed in a very restricted number of plant species. Furthermore, in other experiments, conidial suspension of the fungus affected only mulberry, tulip tree, sweet potato, apple, and Japanese apricot leaves (24). These results suggest that the toxins are host nonspecific, as in the case of the toxins produced by several other Colletotrichum species $(1,2,5,6,8,14)$.

In mulberry leaves, the nonspecific toxins of $C$. dematium appear to be involved in the pathogenesis of the fungus, because the sensitivity to the phytotoxins of each mulberry cultivar correlated

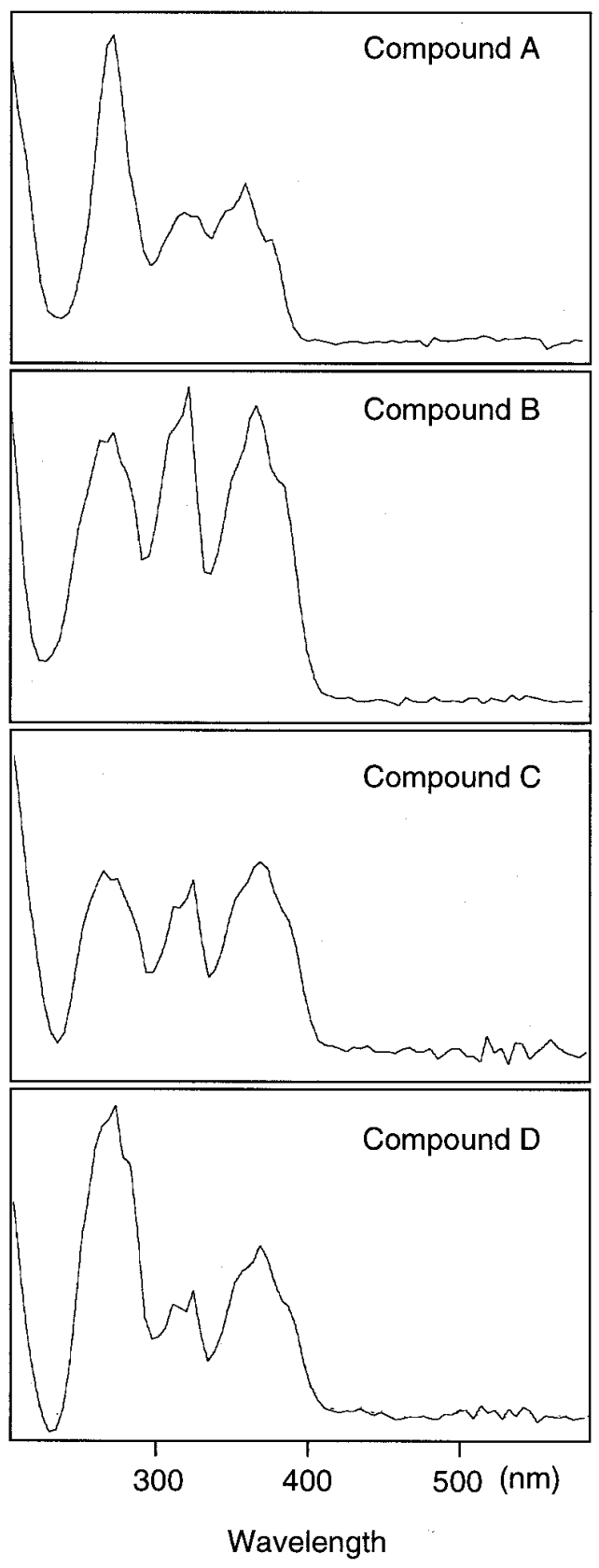

Fig. 5. UV absorption spectra of toxic compounds isolated from anthracnose lesions on mulberry leaves. The spectra were detected with the photodiode array detector (Waters 996 photodiode array detector) on high-pressure liquid chromatography separation. Solvents: compound A, $\mathrm{H}_{2} \mathrm{O} / \mathrm{MeOH} / \mathrm{AcOH}$ (49:50:1); compounds $\mathrm{B}$ and $\mathrm{C}, \mathrm{H}_{2} \mathrm{O}$ /acetonitrile (52:48); and compound $\mathrm{D}$, $\mathrm{H}_{2} \mathrm{O}$ /acetonitrile (60:40). with the extent of fungus infection. Although the fungal conidia did not cause anthracnose lesions on the leaves of resistant cultivars, the infection was revealed to be latent, suggesting that the fungal invasion was not completely inhibited on resistant cultivars. When the fungus causes anthracnose lesions on the leaves, the toxins may be produced in the lesions. The detection of the toxins in diseased leaves started 2 days after the inoculation of conidia, at a time when brown lesions were appearing on the leaves (cv. Shin-ichinose). The quantity of the toxins tended to correlate to the area of the symptoms (data not shown). On the other hand, conidia have been reported to infect leaves within 1 day after inoculation (25). This suggests that the phytotoxins are abundantly produced after fungal invasion and colonization in mulberry leaves and that the fungus continues to produce the toxins with the progression of lesions. In fact, the toxins were found in border areas as well as brown parts of lesions on mulberry leaves, suggesting that the toxins may contribute to the development of the lesions. Dimmond and Waggoner (4) used the term "vivotoxin," for which the criteria are as follows: (i) reproducible separation from the diseased plant, (ii) purification, and (iii) reproduction of at least part of the disease symptoms when the toxin is placed in a healthy plant. Properties of the phytotoxins produced by $C$. dematium in lesions are consistent with the above criteria.

The phytotoxins produced in anthracnose lesions consisted of four active compounds. Yield of each compound was less than $0.1 \mathrm{mg}$ per approximately $650 \mathrm{~g}$ of dried lesion (a content of less than $0.154 \mathrm{ppm}$ in lesion), indicating that toxicity of the compounds to mulberry leaves is very potent. Due to the low yields, the structure of these compounds could not be identified in the study. However, the isolation protocols of the compounds described in the study and the characteristic information about their UV spectra, each showing the same three absorption peaks, may facilitate the identification of these compounds in further studies.

\section{LITERATURE CITED}

1. Bailey, J. A., O' Connell, R. J., Pring, R. J., and Nash, C. 1992. Infection strategies of Colletotrichum species. Pages 88-120 in: Colletotrichum: Biology, Pathology and Control. C.A.B. International, Wallingford, United Kingdom.

2. Ballio, A., Bottalico, A., Buonocore, V., Carilli, A., Di Vittorio, V., and Graiti, A. 1969. Production and isolation of aspergillomarasmin B (lycomarasmic acid) from cultures of Colletotrichum gloeosporioides Penz. (Gloeosporium olivarum Alm.). Phytopathol. Meditterr. 8:187-196.

3. Dasgupta, B. 1986. Role of toxin secretion by Colletotrichum capsici on the expression of leaf spot symptoms in betel vine. J. Plant. Crops 14:36-41.

4. Dimmond, A. E., and Waggoner, P. E. 1953. On the nature and role of vivotoxins in plant disease. Phytopathology 43:229-235.

5. Gohbara, M., Hyeon, S.-B., Suzuki, A., and Tamura, S. 1976. Isolation and structure elucidation of colletopyrone from Colletotrichum nicotianae. Agric. Biol. Chem. 40:1453-1455.

6. Gohbara, M., Kosuge, Y., Yamasaki, S., Kimura, Y., Suzuki, A., and Tamura, S. 1978. Isolation, structures and biological activities of colletotrichins, phytotoxic substances from Colletotrichum nicotianae. Agric. Biol. Chem. 42:1037-1043.

7. Goodman, R. N. 1960. Colletotin, a toxin produced by Colletotrichum fuscum. Phytopathology 50:325-327.

8. Grove, J. F., Speake, R. N., and Ward, G. 1966. Metabolic products of Colletotrichum capsici: Isolation and characterization of acetylcolletotrichin and colletodiol. J. Chem. Soc. Sect. C 230-234.

9. Kimura, K. 1979. The Illustration of Mulberry Diseases in Japan. Kenpakushya, Tokyo.

10. Mitchell, R. E. 1984. The relevance of non-host-specific toxins in the expression of virulence by pathogens. Annu. Rev. Phytopathol. 22:215-245.

11. Narain, A., and Das, D. C. 1970 . Toxin production during pathogenesis of Colletotrichum capsici causing anthracnose of chilies. Indian Phytopathol. 23:484-490.

12. Nishimura, S., and Kohmoto, K. 1983. Host-specific toxins and chemical structures from Alternaria species. Annu. Rev. Phytopathol. 21:87-116.

13. Nishimura, S., and Scheffer, R. P. 1965. Interactions between Helminthosporium victoriae spores and oat tissue. Phytopathology 55:629-634.

14. Ohra, J., Morita, K., Tsujino, Y., Tazaki, H., Fujimori, T., Goering, M., Evans, S., and Zorner, P. 1995. Production of phytotoxic metabolite, fer- 
ricrocin, by the fungus Colletotrichum gloeosporioides. Biosci. Biotechnol. Biochem. 59:113-114.

15. Ouchi, S. 1990. Infection strategies of plant pathogens. Pages 38-60 in: Physiological of Plant Pathology. Buneidou, Tokyo.

16. Pringle, R. B., and Scheffer, R. P. 1964. Host-specific plant toxins. Annu. Rev. Phytopathol. 2:133-156.

17. Shirata, A. 1993. Appearance of the lesion of anthracnose on the mulberry leaves by irradiation with ultraviolet light. Ann. Phytopathol. Soc. Jpn. 59:259-262.

18. Shirata, A., Sugaya, K., Takasugi, M., and Monde, K. 1995. Isolation and biological activity of toxins produced by a Japanese strain of Pseudomonas tolaasii, the pathogen of bacterial rot of cultivated oyster mushroom. Ann. Phytopathol. Soc. Jpn. 61:493-502.

19. Strobel, G. A. 1977. Bacterial phytotoxins. Annu. Rev. Microbiol. 31: 205-224.

20. Suwarto, Gunawan, L. W., Tjitrosomo, S. S., and Pawirosoemardjo, S. 1988. Effect of crude toxin produced by Colletotrichum gloeosporioides on the cell viability on Hevea rubber and tomato plants. Bull. Perkaretan 6:12-20.
21. Walton, J. D., and Panaccione, D. G. 1993. Host-selective toxins and disease specificity: Perspectives and progress. Annu. Rev. Phytopathol. 31:275-303.

22. Wang, J. 1986. In vitro production of toxin by Colletotrichum camelliae Massee. Acta Phytophylacica Sin. 13:151-157.

23. Yoder, O. C. 1980. Toxins in pathogenesis. Annu. Rev. Phytopathol. 18: 103-129.

24. Yoshida, S., and Shirata, A. 1996. Pathogenicity on the leaves of various plants by the mulberry anthracnose fungi. J. Seric. Sci. Jpn. 65:86-93.

25. Yoshida, S., and Shirata, A. 1997. Effect of mulberry leaf components on conidial germination of mulberry anthracnose fungus, Colletotrichum dematium, and observation of early infection processes on the mulberry leaf. Bull. Natl. Inst. Seric. Entomol. Sci. 18:79-96.

26. Yoshida, S., and Shirata, A. 1998. Mulberry anthracnose. Page 195 in: Plant Diseases in Japan. K. Kishi, ed. Zenkoku Nouson Kyouiku Kyoukai, Tokyo.

27. Yoshida, S., Yoshida, S., and Shirata, A. 1995. Differences in the formation of lesions on the leaves infected with anthracnose fungi in mulberry cultivars. Bull. Natl. Inst. Seric. Entomol. Sci. 12:13-30. 